\title{
Modeling in the Classroom: What Approaches are Effective to Improve Students' Writing?
}

\author{
Nancy Maynes and Jeff Scott
}

\author{
Nipissing University
}

\begin{abstract}
Effective writing is a learned skill, required to advance many forms of learning both in classroom contexts, and in job and career contexts. Previous research (Graham \& Perin, 2007) has identified many strategies that promote improvements in students' writing through a metaanalysis of research studies and previous meta-analyses. Other authors and researchers identify approaches to effective teaching (DeRiddler, 2002; Englemann, Becker, Carmine, \& Gersten, 1988; McLaughlin, Gregory, Weber, \& Stookey, 2005; Rosenshine, 1997; Stahl \& Nagy, 2006; Waldrep, 2005). This study uses 10 of the 11 high impact writing strategies identified by previous writing research, as well as more general approaches to effective instruction, to examine the gain scores in three forms of writing by 81 students in Grades 3 to 6 classes to determine the combined effects of high impact approaches to writing on students' ability to write definitions (concept clarification), compare, and write in argumentative formats.
\end{abstract}

Keyword: writing strategies; effective instruction 


\section{Modeling in the Classroom: What Approaches are Effective to Improve Students' Writing?}

The value of learning to write well is a foundational skill in schools and in post-school work contexts. Much of the work students are required to produce at all levels of schooling involves some form of writing. Much of the assessment work done by teachers requires students to produce some form of writing as evidence of their learning. School writing applications and goals are varied (Diamond, 1999; Graham, 2006) and include many forms of writing, related to specific purposes. Analysis of local curriculum guidelines related to writing expectations in language contexts uncovers the goals of having students write in many formats for the purposes of entertaining, explicating, informing, exploring, chronicling, persuading, and defending.

Writing is also a learning tool. Through writing, students can learn to clarify their own thoughts, relate ideas and concepts (Bangert-Drowns, Hurley, \& Wilkenson, 2004; Graham \& Perin, 2007), and review inherent connections in new learning. A focus of language instruction is the improvement of writing skills for both school and post-schooling applications.

Many employment contexts require writing as a method of doing business, as well as a standard to support employment and promotion within a wide range of jobs. Many jobs require communication facilitated through written formats via email, web-based connections, or more traditional letter and report formats. Writing is an aspect of social networking, which is increasingly in use as a communication tool for educational and social applications. Increasing numbers of students are seeking some form of post-secondary education, where the approaches to learning require many forms of writing for both learning and demonstrating learning.

In the local context, writing is one of the three major foci of provincially mandated third party assessments required for provincial accountability measures. Along with measures of reading and basic mathematics skills, writing skill measures are providing public accountability data that are being used to focus school improvement goals, allocate resources, direct professional development, and profile school successes.

\section{Theoretical Framework}

Writing is a complex skill requiring students to learn ways to manage content, while applying a number of skills to display the content in ways that are effective with the intended readers of their written work (Bereiter \& Scardamalia, 1982; Flower \& Hayes, 1980; Scardamalia \& Bereiter, 1991). While a considerable amount of attention is given to various forms of writing in schools, many jurisdictions report below goal writing achievement on standardized assessments (EQAO, 2010). Graham and Perin (2007) suggest that one possible reason why students' writing efforts may not approach required standards is because teachers are not doing a effective enough job of teaching writing. A focus for improvement of this historical outcome has been to teach teachers to unpack or deconstruct the skills required in more complex forms of writing so that those subskills can become the focus of instruction. Unpacking the subskills involved in more complex forms of writing is a strategy that has the potential to support teachers' reflective practice in relation to the teaching of writing, and thereby, to support improvements in students' achievement in relation to this critical skill.

Research about approaches to teaching writing has been prolific in the language field. Typical research-focused approaches to writing isolate a single approach and attempt to measure the impact of a single treatment designed to improve one aspect of writing. Since 1986, there have been several meta-analysis studies conducted to attempt identification of strategies that 
have high impact on writing outcomes (Bangert \& Drowns et al., 2004; Goldring, Russell, \& Cook, 2003; Graham, 2006; Graham \& Harris, 2003; Hillocks, 1986;) and result from such single variable research approaches. A stringent analysis of the body of writing research was undertaken by Graham and Perin in 2007. The strength of this latest meta-analysis was its focus on attempting to sort and analyze previous studies by identifying their strengths and weaknesses as methods of research related to experimental writing intervention. This meta-analysis attempted to identify high quality research studies that addressed the focus of isolating promising instructional practices that could be expected to improve the quality of students' writing. The variety of treatments that were examined in this extensive meta-analysis combined approaches that drew from different theoretical bases for writing, including approaches informed by cognitive theory (Hayes, 2000), social and/or contextual approaches (Prior, 2006; Pritchard \& Honeycutt, 2006), self-regulation approaches (Sperling \& Freedman, 2002; Zimmerman \& Risenberg, 1997), schema theory (Anderson \& Pearson, 1984) and discourse theory (Chafe \& Tammen, 1987).

The Graham and Perin (2007) meta-analysis of bodies of writing research identified 11 strategies shown to improve aspects of writing in experimental studies that were analyzed for the strength of the approach used in the studies. These 11 writing instruction strategies include setting specific, reachable product goals for the writing assignment; using computers as an instructional support for writing tasks; explicit teaching of sentence combining techniques; instruction in the pre-writing tasks of organization and idea generation; teaching data management approaches specific to forms of inquiry that support idea development and strengthen content for writing; using process writing approaches that allow for extended writing opportunities; authentic writing task engagement; conference-style, personalized scaffolding during writing; clear engagement in the processes of a writing cycle; providing models and exemplars of the expected writing products accompanied by structured opportunities to analyze the examples; and application of writing as a learning to learn tool so that writing was employed to learn new content.

The common feature of all of these successful research approaches to improving writing is the emphasis on the impact of explicit strategy instruction, whether process approaches are also embedded in the strategy or not. Process approaches are by their nature explicit strategy focused. Explicit strategy instruction is characterized by the timely and responsive use of instruction that teaches students how to write for specific purposes, targets support as writing tasks are undertaken, provides timely and specific feedback to focus improvement efforts, gives instruction in specific subskills of the task (e.g., punctuation, paragraphing, sentence combining), and provides models or exemplars, including teaching students to use rubrics that clarify targeted standards as growth schemes to work toward in their own writing tasks. Each of these approaches seeks to solidify skills for writing in ways that have the potential to support students' independent use of the skill or approach following instruction.

Explicit or direct instruction (although the original use of direct instruction referred to scripted teaching methods) has a long history in public education endeavors. However, the use of specific approaches with the potential for high yield outcomes may be challenged by what Graham (2007) refers to as delivery issues. That is, the researched strategies with potential have been identified but they may not be employed effectively in classrooms to improve writing outcomes. The delivery issues may, at least in part, be attributed to the vastly different realities 
of research contexts and real classroom contexts where many approaches may be used in conjunction.

To consider ways to leverage the use of known effective strategies, a model was needed to support teacher candidates' developing conceptions of the elements of direct instruction and the instructional actions that would support explicit or direct teaching of any specific strategies for writing. When planning for instruction, the teacher can choose either a direct (explicit) instruction approach or an indirect approach such as cooperative learning, activity centers, projects, contract learning, project-based learning, inquiry, and/or computer-directed instruction. Research has highlighted that teachers may not be as strong at providing direct instruction, or as clear about what actions constitute direct instruction, as we might expect based on our knowledge of the efficacy of this approach (DeRiddler, 2002; Englemann, Becker, Carmine, \& Gersten, 1988; Gersten, Carmine, \& Woodward, 1987; Lloyd, Cullinan, Heins, \& Epstein, 1980; McLaughlin, Gregory, Weber, \& Stookey, 2005; Stahl \& Nagy, 2006; Waldrep, 2005). In response to the need to clarify the steps of explicit, direct instruction in a teacher preparation program, we developed a graphic representation of the phases of instruction (see Figure 1 ) that was then used to support the design of our approach to improving writing instruction in the research context of this study.

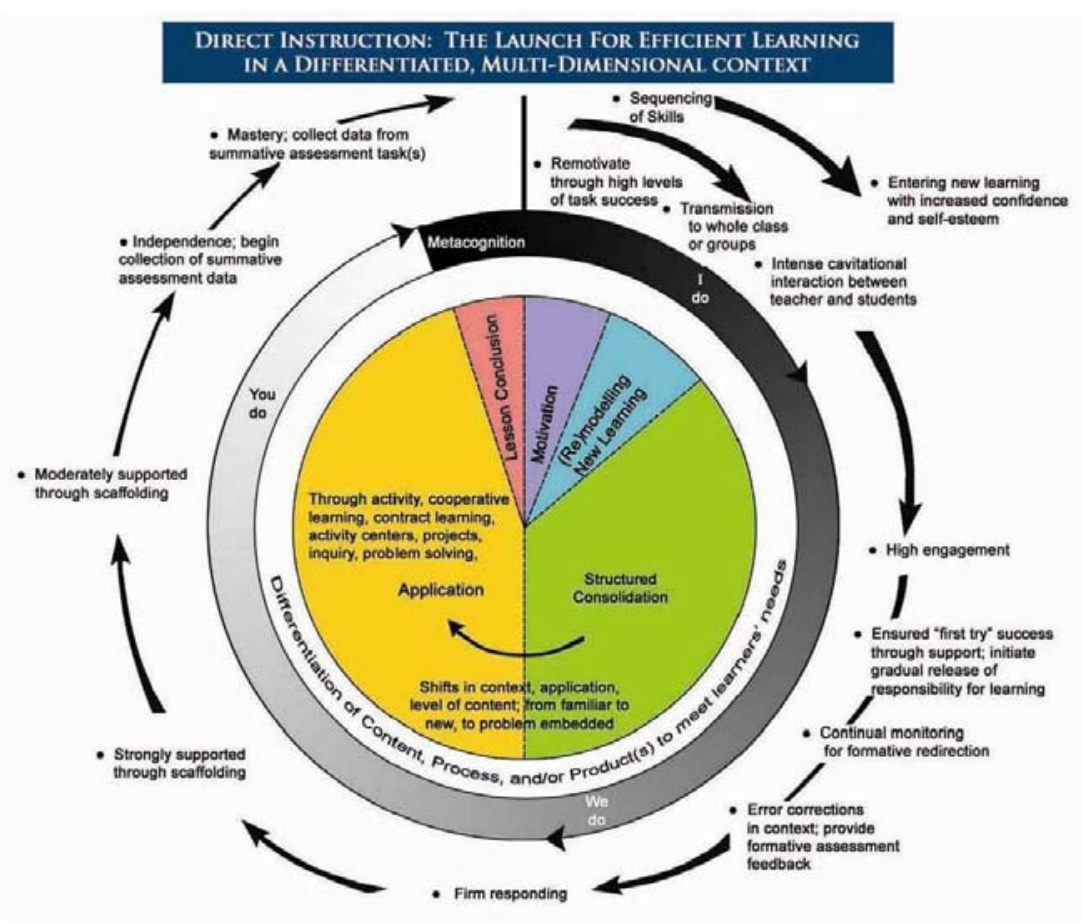

Figure 1. Phases of instruction involving modeling

While it is beyond the scope of this paper to examine this model in detail, such detail can be found in other papers (Maynes, Dunn, \& Julien-Schultz, 2010a; 2010b). The critical aspect 
that informed the current study was the relationship between the explicit instruction of many strategies and the supports, practice opportunities, applications, and feedback that guided students' practice with newly taught skills, using 10 of the 11 approaches identified by Graham and Perin (2007). This model also supports the instructional sequence for new learning identified by many other researchers (Duke \& Pearson, 2002; Fisher \& Frey, 2008; Fisher, Frey, \& Lapp, 2008; Fullan, Hill, \& Crevola, 2006; Hattie \& Timperley, 2007; Hill \& Flynn, 2006).

\section{Problem Identification}

While the work of Graham and Perin (2007) is a crucial contribution to our body of knowledge about writing instruction and the potential of several high yield strategies to promote writing achievement, the instructional challenge of that meta-analysis is identified by its authors. Graham and Perin (2007) explain that the meta-analysis does not reveal the combination of activities nor the saturation of each that is needed to maximize writing instruction for students. This acknowledges the relative complexity of real instructional applications in classrooms in contrast to the single variable approaches typical of a research focus. If we use the strategies revealed by the Graham and Perin (2007) meta-analysis of high yield and high validity studies of writing completed over the past 30 years as a starting point for classroom research, we can learn about the combined impact of promising strategies on specific writing tasks. The challenge we set for ourselves was this: What impact would a combination of high yield writing strategies have on three forms of complex writing tasks with students from Grades 3 to 6 ?

\section{Methodology}

A school board superintendent, who was our research contact, randomly selected four classrooms that met the following criteria: a school improvement goal of focusing on writing improvements in students from Grades 3 to 6; an accessible location of the schools to the researchers; the willingness of the classroom teachers to engage in research in their regular classroom environment; a breadth of age range among the students with those targeted by mandated external assessments at the Grades 3 and 6 levels being the bookends of the age group; and, the willingness of parents of these students to provide research access.

Eighty-one students between 8 and 12 years old participated in the study. Gain scores (pre and posttests) were used to calculate the impact of the instructional treatment. Local curriculum guidelines were analyzed to identify three forms of writing that would be taught in the study. All three forms of writing were target forms of writing for the grade levels encompassed in this study. These writing forms included: writing definitions (which we termed concept clarification), comparing, and argumentative writing. All three forms of writing were found to be included in external assessments in recent provincial tests of students' writing achievement, making them valued forms for writing in the curriculum, and supporting the guideline mandates to address instruction in these forms of writing.

The experimental treatment of each of the three forms of writing included the use of 10 of the 11 high impact strategies identified in the Graham and Perin (2007) meta-analysis. Through a series of classroom lessons, students were taught each form of writing by: setting specific, reachable product goals for the writing assignment; explicit teaching of sentence-combining techniques and other forms of sentence design; instruction in the prewriting tasks of organization and idea generation; teaching data management approaches specific to forms of inquiry that support idea development and strengthen content for writing; using process writing approaches that allow for extended writing opportunities; authentic writing task engagement; conference- 
style, personalized scaffolding during writing from three adults; clear engagement in the processes of a writing cycle, providing models and exemplars of the expected writing products accompanied by structured opportunities to analyze the examples; and, application of writing as a learning to learn tool so that writing was employed to learn new content. We referred to this combination of strategies as Cavitational Modeling. The only high impact strategy not used in our experimental treatment was the use of computers and word processing to support writing tasks. This approach was not used because computer technology was neither readily nor equitably available across all treatment subjects because of technology limitations and access issues in some schools. The combined use of the other eleven strategies addressed the issue of realistic implementation provided in the discussion of the Graham and Perin (2007) metaanalysis.

Lessons in the three writing approaches spanned a 2-month time period with teaching blocks averaging 50 minutes three times per week for a total contact average time of 20 hours. Writing efforts from each contact time were evaluated against pre-established and precommunicated criteria and written feedback was provided for each student about their writing progress through comments directing students to specific areas for personal growth and a summative score between 1 and 4; 4 was the target level of achievement for each task. Teachers were provided with a checklist of progress for their class during each contact and a cumulative assessment of each writing task at the end of the treatment.

During lessons, researchers were guided in their treatment design by Rosenshine's (1997) approach to direct instruction. This background formed the basis of our approach to applying the 11 high impact strategies noted by Graham and Perin (2007). Rosenshine (1997, 1990) summarized much of the cognitive research of the last 30 years to identify critical strategies used by effective teachers to ensure learning. He referred to these critical strategies as the Functions for Teaching Well-Structured Tasks. Writing is certainly a well structured task. Rosenshine's (2007) summary of these actions includes the following:

- review (motivation, a hook, or the surfacing of prior knowledge) including reviewing homework, relevant previous learning, and the prerequisite skills and knowledge for the day's lesson;

- presentation, including modeling the new learning (as per the direct instruction diagram presented earlier), stating lesson goals and providing an outline or agenda for the time together, presenting the material in small steps, modeling procedures, and providing positive and negative examples as models or exemplars;

- using clear language, and avoiding digressions;

- providing guided and heavily scaffolded, timely practice, including practice until comfort with the skill was evident;

- frequent individual and group checking for understanding through questioning; regular, targeted, timely and detailed feedback;

- insurance of high levels of task success, and maintenance of practice opportunities until fluency was evident across subjects;

- $\quad$ ongoing guided practice supported by corrections and formative feedback specific to task targets; supportive feedback to enhance confidence; sustained feedback, cues and reteaching as needed; 
- independent practice supported by on-demand assistance; active supervision and differentiated supports; and

- reviews of each contact time learning goal to create metacognitive awareness and support students' growing awareness of their strengthening strategies (strategy efficacy).

To set specific, reachable goals for each treatment contact time, we deconstructed the three writing skills into manageable subskills that would develop students' complex skills sets over the treatment time. Each of these manageable subskills would become a pre- and post-test variable to guide analysis of the complex writing skills of concept clarification (definitions), comparison, and argumentative writing. Twenty-eight variables were identified for pre- and posttest analysis.

Pre-and post-scores on the 28 variables that identified the characteristics students' writing we wanted to measure (see Table 1 ) were collected from the 81 students. Students were in Grades 5/6 (3 classrooms; $n=61$ ) and 3/4 ( 1 classroom; $n=20)$. Gain scores were calculated on each variable by analyzing the three types of writing submitted prior to treatment and following the treatment.

Most of the variables were assessed on a 5-point scale (0-4); however, two were assessed on a 3-point scale (0-2) and five were coded on a 4-point scale (0-3); these variations reflected the anticipated observable variations in writing that researchers were able to identify for each of the subskills. Pre- and post-test codings were conducted by a trained research assistant (RA). Inter-rater agreement between the Principal Investigators (PI) and the RA was investigated on 10 cases, using Intraclass Correlation Coefficients (ICC); the ICC was acceptable for all variables (Table 1 ). To determine whether the sample improved follow the training, repeated measures $t$ tests were conducted on all 28 variables. A total score was also computed by summing the score assigned to each variable. To ensure internal consistency for the 28 variables, separate Chronbach's Alphas were calculated for the two time points and were found to be acceptable at pre-training (pre $\alpha=.65$ ) and excellent at post-training (post $\alpha=.90$ ). Students improved significantly on 27 of the 28 criteria being measured (Table 1; coded here as $\mathrm{C} 1, \mathrm{C} 2$, etc.). Only students' ability to state their decision clearly did not change significantly from pre- to postmeasures. 


\section{Table 1}

Paired Samples Statistics and Intraclass Correlation Coefficients

\begin{tabular}{|c|c|c|c|c|}
\hline $\begin{array}{c}\text { Writing Quality } \\
\text { Variable }\end{array}$ & $\begin{array}{c}\text { Pre } \\
M(\mathrm{SD})\end{array}$ & $\begin{array}{c}\text { Post } \\
M(\mathrm{SD})\end{array}$ & Scoring scale & ICC \\
\hline C 1 & $2.91(.48)$ & $3.54(.50)$ & $0-4$ & 1.0 \\
\hline C 2 & $1.32(1.30)$ & $2.26(1.20)$ & $0-3$ & 1.0 \\
\hline C 3 & $3.16(1.129)$ & $3.64(.811)$ & $0-4$ & 1.0 \\
\hline $\mathrm{C} 4$ & $1.25(1.290)$ & $2.42(1.203)$ & $0-4$ & .96 \\
\hline C 5 & $.16(.402)$ & $2.38(.784)$ & $0-4$ & 1.0 \\
\hline C 6 & $.11(.387)$ & $2.96(1.327)$ & $0-4$ & 1.0 \\
\hline C 7 & $.44(.758)$ & $3.16(1.089)$ & $0-4$ & 1.0 \\
\hline C 8 & $.12(.430)$ & $2.44(1.183)$ & $0-4$ & 1.0 \\
\hline C 9 & $.00(.000)$ & $2.42(1.150)$ & $0-3$ & 1.0 \\
\hline C 10 & $.00(.000)$ & $2.69(1.384)$ & $0-4$ & 1.0 \\
\hline C 11 & $.60(.944)$ & $1.99(1.654)$ & $0-4$ & 1.0 \\
\hline C 12 & $.04(.247)$ & $1.84(1.250)$ & $0-4$ & 1.0 \\
\hline $\mathrm{C} 13$ & $.56(.935)$ & $1.84(1.250)$ & $0-4$ & .94 \\
\hline C 14 & $.00(.000)$ & $3.23(1.309)$ & $0-4$ & .93 \\
\hline C 15 & $.00(.000)$ & $3.07(1.289)$ & $0-4$ & 1.0 \\
\hline C 16 & $.02(.128)$ & $1.72(.686)$ & $0-2$ & 1.0 \\
\hline $\mathrm{C} 17^{*}$ & $1.93(.359)$ & $1.97(.256)$ & $0-2$ & 1.0 \\
\hline C 18 & $.00(.000)$ & $2.13(1.348)$ & $0-3$ & 1.0 \\
\hline C 19 & $.00(.000)$ & $2.18(1.756)$ & $0-4$ & 1.0 \\
\hline C 20 & $.02(.128)$ & $.92(1.453)$ & $0-4$ & 1.0 \\
\hline C 21 & $.00(.000)$ & $2.03(1.402)$ & $0-3$ & .81 \\
\hline C 22 & $.00(.000)$ & $2.02(1.335)$ & $0-3$ & .90 \\
\hline C 23 & $.43(.718)$ & $.87(1.396)$ & $0-4$ & .63 \\
\hline C 24 & $.64(.875)$ & $2.38(1.583)$ & $0-4$ & 1.0 \\
\hline C 25 & $.00(.000)$ & $1.54(1.361)$ & $0-4$ & .98 \\
\hline C 26 & $1.63(.872)$ & $2.0(.806)$ & $0-4$ & 1.0 \\
\hline C 27 & $.81(.726)$ & $2.15(.792)$ & $0-4$ & 1.0 \\
\hline C 28 & $.02(.156)$ & $2.14(.945)$ & $0-4$ & 1.0 \\
\hline Total score & 15.43 & 58.84 & \multicolumn{2}{|c|}{ Mean Change - 43.41} \\
\hline
\end{tabular}

All $t$ 's $>-23.97$, all $p$ 's $<.001$ except $* t=0.57, p>.05$

Each of the 28 variables, identified as $\mathrm{C} 1$ to $\mathrm{C} 28$ in Table 1, is expanded as a specific subskill of one of the three targeted forms of writing (Table 2). 


\section{Table 2}

Subskills Taught for the Writing Skills of Concept Clarification, Comparison, and Argumentative Writing

\author{
COMPLEX SKILL \\ Concept Clarification (writing \\ definitions)
}

\section{Comparison/ Comparative} Writing

Comparison/ Comparative Writing (con't)

\section{Argumentative/ Persuasive Writing}

\section{Language Skills}

\section{DECONSTRUCTION OF THE COMPLEX SKILL FOR INSTRUCTIONAL PURPOSES USING \\ CAVITATIONAL MODELING}

$\mathrm{Cl}$ - uses the concept name in the definition

$\mathrm{C} 2$ - puts the concept into a clear and accurate class of items

C3 - defines the concept by using four or more characteristics

C5 - characteristics used in the definition allow for differentiation between this item and others in its class

C6 - uses a two dimensional framework to plan a comparison

$\mathrm{C} 7$ - applies criteria to a comparison in a systematic (to all options equally) way

$\mathrm{C} 8$ - identifies common criteria that reflect at least three aspects of the topic

C9 - formulates an opening paragraph that identifies the topic, subtopics, and criteria that will be used in the comparison

$\mathrm{C} 10$ - structures comparative paragraphs to reflect application of individual criteria applied to all sub-topics

C11 - generates opening sentences that structure application of criteria within paragraphs across all sub-topics (not within opening or closing paragraphs)

$\mathrm{C} 12$ - uses appropriate connecting words to show similarities, differences, and cause and effect relationships (between topics)

$\mathrm{C} 13$ - formulates a closing paragraph that provides a review and reaction on the sub-topics that were compared

C14- writes compound and/or compound-complex sentences to compare

C15 - uses a two dimensional framework to plan an appropriate decision

C16 - generates three or more criteria to consider options in a planning chart

C17 - applies weighting of criteria sy stematically to options and criteria (in a planning chart)

C18 - states decision clearly

C19- options are outlined in an opening paragraph

$\mathrm{C} 20$ - criteria are outlined in an opening paragraph

$\mathrm{C} 21$ - relative values of argumentative criteria are outlined in an opening paragraph

$\mathrm{C} 22$ - structures paragraphs to reflect systematic consideration of each option in relation to each criterion

C23 - generates opening sentences that structure consideration of cach option in relation to each criterion

C24 - uses appropriate transition words to show relationships among ideas

C 25 - writes compound and/or compound/complex sentences to create relative statements

C26 - formulates a closing paragraph that provides review and reaction on each of the options

$\mathrm{C} 27$ - writes legibly

C28 - uses opening sentences effectively 


\section{Interpreting the Data}

Intensive interaction with researchers to learn to write using three locally mandated forms of writing resulted in positive gains across all members of the experimental group. Parenthetically, students with special needs were not separated from the classroom groups for any aspects of this study. We hypothesized that good instruction for the whole group would support the special learning needs of every student and allowed for individual scaffolding throughout the learning, regardless of identified needs.

The 28 variables that were individually assessed as aspects of the three forms of writing in this study were examined in pre- and post-test writing samples of definitions (concept clarification), comparison, and argumentative writing. The researchers and research assistant scored each of the 28 variables on the scales as outlined previously in Table 1 . All variables showed highly significant gains with the exception of students' ability to state their decision. This lack of gain on this score appears to reflect students' ability to make a simple decision (e.g., What will I do to celebrate a relative's birthday?) based on an unstated criterion even though the targeted skill for argumentative writing taught the employment of multicriterion decision making for more complex decisions.

In the three forms of writing, 27 of the 28 variables being examined in students' pre- and post-test writing showed highly significant gains due to treatment instruction. We attribute these significant gains to the deliberate use of high impact strategies revealed through previous research; the clarity of our own conception about approaches to modeling and the gradual release of responsibility; and the precision teaching of the 28 targeted subskills that supported each form of writing (Table 2).

As stated by Graham and Perin (2007) in their meta-analysis study, there was a need to address the impact of a combination of activities to determine the impact of such a combination on students' writing. Fullan, Hill, and Crevola (2006) refer to the strongest teaching as precision teaching, which is targeted at supporting students' acquisition, practice, and independent use (application) of identified skills. By taking these approaches in our study and engaging students in intense and prolonged writing improvement tasks, we were able to achieve strong writing improvements in all three forms of writing which reflect writing achievement goals in local curriculum guidelines.

\section{Discussion}

Graham (2007) discusses the writing strategies that hold researched promise for improvement of writing instruction as "big ticket effects" (p. 6). These big ticket effects are desirable outcomes for writing instruction with students. Specific strategies, precision teaching of targeted subskills of writing, and opportunities for students to experience individualized, scaffolded support of writing efforts throughout writing tasks are crucial elements of effective writing instruction, and we would argue, aspects of the precision teaching of any skill. These approaches are reflected in our model for direct instruction and made possible by identifying and deconstructing the subskills in the three forms of writing we chose to address.

This study has built on the work of Graham \& Perin (2007) by examining the impact of a combination of 10 of the 11 high impact strategies that previous research has identified as having the potential for big ticket effects. The direct instruction graphic helped us to maintain a focus on the various aspects of instruction with each of the 10 strategies as the 20 hours of writing 
instruction unfolded with each of the four classes of students in this research group. This focus ensured that each instructional contact was delivering precision teaching of one or more of the targeted skills that are subskills of the overall three writing formats.

The Graham and Perin (2007) meta-analysis of writing studies demonstrated that how we teach writing skills matters to the outcomes of writing skill instruction. Our study has shown that individual strategies can be combined in reflective and responsive ways to sequence precise and skill-focused writing instruction. The concept of direct and precise instruction in these writing skills was informed by the work of previous researchers such as Fisher and Frey (2008), Fullan, Hill and Crevola (2006), Rosenshine $(1997,1990)$ and our own model of direct instruction.

\section{Limitations}

When a number of approaches are used in a research treatment, it is difficult to impossible to attribute the effects of the treatment to any specific cause. This is the true nature of teaching in a classroom. The work of Graham and Perin (2007) and previous researchers, who conducted meta-analysis studies, provides valuable insights about specific strategies that have instructional potential. The recognition of Graham and Perin (2007) that their research was limited by the isolated nature of the impacts of single researched strategies and the gap between research and classroom implementation provides opportunities to consider the role of research as information for classroom implementation. However, the day-to-day instruction in a classroom is much more complicated than the single variable conditions that typify research approaches. The down side of this is the inability to be precise about which approaches have which impacts when a combination of high potential strategies is implemented in classroom instruction. The role of research in education is to provide guidance for classroom instruction and this end is achieved through the use of combined high impact approaches to learning tasks.

Evidence-based writing practices that result from high quality research inform classroom practices in writing instruction. Attempting to combine many evidence-based practices to strengthen instruction in three mandated forms of writing was a challenging task in terms of many considerations. Over 80 hours of contact time with research subjects was one demanding aspect of this study. It brings into focus the decisions that teachers must make as they address mandated learning goals for any subject area. How much time can they devote in the regular classroom day to getting any one skill "right"? In addition to the contact time, every aspect of students' daily writing was thoroughly analyzed against pre-established and pre-communicated criteria. In addition to pre- and post-test writing samples, each of the 81 participants produced writing samples in each of the three formats for the purposes of practice and moved toward gradual independence with each writing format. Each piece of writing was analyzed and formative feedback given between research treatment times. This created a very demanding schedule that intensified the data collection process. Such intensity may not be sustainable over the longer term in regular classrooms where other subject demands also require the teacher's planning and assessment attention.

Finally, because four classrooms and a 5-year age span were involved in the different groups in this study, we have not sought to attribute nor examine any effects that may relate to maturation. Each student served as their own base line for measuring change in the pre- and posttest context. We cannot, therefore, make any claims about the possible impact of age and schooling experience on the results of this study. 
The transfer of research effects into classroom contexts is complex. Single variable applications of strategies are not reflective of the reality of busy classrooms. By demonstrating the combination of strategies garnered from high impact strategies in this research context, we have tried to show how teachers can benefit from the ideas of researched approaches and apply these in context while still using mandated curriculum requirements as their starting point. Our approach in this study gave attention to most of the high impact writing improvement strategies identified by previous researchers. We recognized the pivotal role of modeling in writing instruction as this was found by Graham and Perin (2007) to be the most powerful of the individual writing intervention strategies shown in previous single strategy studies. By deconstructing the mandated writing tasks, employing big ticket strategies, and maintaining a focus on precise instructional actions informed by a clear conception of direct instruction, we believe that the results we have achieved with teaching these three forms of writing are transferrable to most, if not all, classrooms. 


\section{References}

Anderson, R., \& Pearson, D. (1984). A schema-theoretic view of basic process in writing. In D. Pearson (Ed.), Handbook of reading research (pp. 378-455). New York, NY: Longman.

Bangert-Drowns, R. L., Hurley, M. M., \& Wilkenson, B. (2004). The effects of school-based Writing-to-Learn interventions on academic achievement: A meta-analysis. Review of Educational Research, 74, 29-58.

Bereiter, C., \& Scardalalia, M. (1982). From conversation to composition: The role of instruction in a developmental process. In R. Glaser (Ed.), Advances in instructional psychology, Vol. 2 (pp. 1-64). Hillsdale, NJ: Erlbaum.

Chafe, W., \& Tannen, D. (1987). The relation between written and spoken language. Annual Review of Anthropology, 16, 383-407.

DeRidder, I. (2002). Visible or invisible links: Does the highlighting or hyperlink affect incidental vocabulary learning, text comprehension, and the reading process? Language, Learning \& Technology, 6, 123-149.

Diamond, J. (1999). Guns, germs and steel: The fates of human societies. New York, NY: Norton.

Duke, N.K., \& Pearson, P.D. (2002). Effective practices for developing reading comprehension. In A. E. Farstup \& S. E. Samuels (Eds.), What research has to say about reading instruction (pp.205-242). Newark, DE: International Reading Association.

Englemann, S., Becker, W. C., Carnine, D., \& Gersten, R. (1988). The direct instruction follow through model: Design and outcomes. Education and Treatment of Children, 11, 303-317.

Education Quality and Accountability Office (EQAO), (2010). Retrieved from: eqaoweb.eqao.com/eqauweborgprofile/profile.aspx?_Mident...E

Fisher, D., \& Frey, N. (2008). Better learning through structured teaching: A framework for the gradual release of responsibility. Alexandria, VA: Association for Supervision and Curriculum Development.

Fisher, D., Frey, N., \& Lapp, D. (2009). In a reading state of mind. Newark, DE: International Reading Association.

Flower, L., \& Hayes, J. (1980). The dynamics of composing: Making plans and juggling constraints. In L. Gragg, \& R. Steinberg (Eds.), Cognitive process in writing (pp. 31-50). Hillsdale, NJ: Lawrence Erlbaum Associates.

Fullan, M., Hill, P., \& Crevola, C. (2006). Breaktthrough. Thousand Oaks, CA: Sage.

Gersten, R., Carnine, D., \& Woodward, J. (1987). Direct instruction research: The third decade. Remedial and Special Education, 8(6), 48-56.

Goldring, A., Russell, M., \& Cook, A. (2003). The effects of computers on student writing: A meta-analysis of studies from 1992-2002. Journal of Technology, Learning, and Assessment, 2, 1-51.

Graham, S. (2006). Strategy instruction and the teaching of writing: A meta-analysis. In C. MacArthur, S. Graham, \& J. Fitzgerald (Eds.), Handbook of writing research (pp. 187207). New York, NY: Guilford. 
Graham, S. (2007). Write-minded. Writing Next. Retrieved from www.all4ed.org/publications/WritingNext/index.html

Graham, S., \& Harris, K. R. (2003). Students with learning disabilities and the process of writing: A meta-analysis of SRSD studies. In L. Swanson, K.R. Harris, \& S. Graham (Eds.), Handbook of research on learning disabilities (pp. 322-344). New York, NY: Guilford.

Graham, S., \& Perin, D. (2007). A meta-analysis of writing instruction for adolescent students. Journal of Educational Psychology, 99(3), 445-476.

Hattie, J., \& Timperley, H. (2007). The power of feedback. Review of Educational Research, 77 (1), 81-112.

Hayes, J. R. (2000). A new framework for understanding cognition and affect in writing. In R. Indrisano, \& J.R. Squire (Eds.), Perspectives on writing: Research, theory and practice (pp. 6-44). Newark, DE: International Reading Association. (Original work published in 1996. In C.M. Levy, \& S. Randsell (Eds.), The science of writing: Theories, methods, individual differences, and applications (pp.1-27). Mahwah, NJ: Erlbaum.)

Hill, J., \& Flynn, K. (2006). Classroom instruction that works with English language learners. Alexandria, VA: ASCD.

Hillocks, G. (1986). Research on written composition: New directions for teaching. Urbana, IL: National Council of Teachers of English.

Lloyd, J., Cullinan, D., Heins, E.D., \& Epstein, M. H. (1980). Direct instruction: Effects on oral and written language comprehension. Learning Disabilities Quarterly, 3, 70-76.

Maynes, N., Julien-Schultz, L., \& Dunn, C. (2010). Managing direct and indirect instruction: A visual model to support lesson planning in pre-service programs. The International Journal of Learning, 17(2), 125-139.

Maynes, N., Julien-Schultz, L., \& Dunn, C. (2010). Modeling and the gradual release of responsibility: What does it look like in the classroom? Brock Education, 19(2), 65-77.

McLaughlin, T. F., Gregory, A., Weber, K. P., \& Stookey, S. (2005). The effect of using direct instruction and re-reading contingency with a high school student. International Journal of Special Education, 20(1), 50-54.

Prior, P. (2006). A sociocultural theory of writing. In C. MacArthur, S. Graham, \& J. Fitzgerald (Eds.), Handbook of writing research (pp. 54-66). New York, NY: Guilford.

Pritchard, R. J., \& Honeycutt, J. (2006). Process writing. In C. MacArthur, S. Graham, \& J. Fitzgerald (Eds.), Handbook of writing research (pp. 275-290). New York, NY: Guilford.

Rosenshine, B. (2007). Systematic Instruction. In T.L. Good (Ed.) 21st century education: A reference handbook. California: SAGE Publications.

Rosenshine, B. (1990). Explicit teaching and teacher training. Educational Psychology, 41(4), 34-44.

Rosenshine, B. (1997). Advances in research on instruction: Issues in educating students with disabilities (197-221). Mahwah, N.J: Lawrence Erlbaum. 
Scardamalia, M., \& Bereiter, C. (1991). Literate expertise. In K.A. Ericsson, \& J. Smith (Eds.), Toward a general theory of expertise: Prospects and limits (pp. 172-194). Cambridge, UK: Cambridge University Press.

Sperling, M., \& Freedman, S. W. (2002). Research in writing. In V. Richardson (Ed.), Handbook of research in teaching ( $4^{\text {th }}$ ed., pp. 370-389). Washington, DC: American Educational Research Association.

Stahl, S. A., \& Nagy, W. E. (2006). Teaching word meanings. Mahwah, N. J: Lawrence Erlbaum.

Waldrep, R. (2005). Soaring to the top: Temple Elementary School, Orbit, 35(3), 23.

Zimmerman, B., \& Risemberg, R. (1997). Become a self-regulated writer: A social cognitive perspective. Contemporary Educational Psychology, 22, 73-101. 